\title{
Study of student's self-isolation adaptation strategies during the Covid-19 pandemic
}

\author{
Nadezhda Sivrikova ${ }^{1 *}$, Elena Chernikova ${ }^{1}$, Elena Kharlanova $^{1}$, Tatyana Ptashko $^{1}$, Artem \\ Perebejnos ${ }^{1}$, and Irina Ryabykh $^{2}$ \\ ${ }^{1}$ South Ural State Humanitarian Pedagogical University, Department of Social Work, Pedagogy and \\ Psychology, Chelyabinsk, Russian Federation, Lenin prospect 69, Russia \\ ${ }^{2}$ South Ural State Humanitarian Pedagogical University, Department of geography and methods of \\ teaching geography, Chelyabinsk, Russian Federation, Lenin prospect 69, Russia
}

\begin{abstract}
The COVID-19 epidemic, which turned into a pandemic, has led to the introduction of lockdown in many countries as a measure to prevent the spread of the virus. Significant changes have occurred in the lives of Russian students. The research objective is to study students' strategies of adaptation to the self-isolation caused by the need to prevent the spread of COVID-19. To achieve this purpose, an online survey of students was conducted, followed by a correlation analysis of the data. The survey involved 269 students aged 17-21. In self-isolating conditions, students prefer to use strategies aimed at self-change. Two groups of strategies are distinguished in the structure of students' adaptive behavior, between which there are positive correlations of average strength. The first group includes students' preferable behavior strategies (accommodating, self-change, and self-immersion). The second group consists of strategies that are not popular among students (environment changing, waiting, avoidance, and passive self-representation). Male students are more active in solving problems than female students. The research results expand the existing understanding of students' reactions to changes related to selfisolation. They can be useful to teachers, psychologists involved in assessing the social consequences of the COVID-19 pandemic on students.
\end{abstract}

\section{Introduction}

The rapid transition of the COVID-19 epidemic into a pandemic has become a real challenge for society. The pandemic triggered a major medical crisis affecting many countries [1]. The World Health Organization (WHO) has recommended quarantine measures to prevent the spread of the disease [2]. Many countries have followed this recommendation and introduced a lockdown for citizens [3]. The psychological and behavioral responses of the entire population to a lockdown play a decisive role in combating the COVID-19 outbreak.

Studies have shown that social isolation leads to negative psychological and psychosocial consequences [4]. Forced loneliness is a powerful factor that enhances stress

* Corresponding author: boboronv@cspu.ru 
and stress reactions in both humans [5-7] and animals [8,9]. Consequently, social distancing during outbreaks of infectious diseases, necessary to reduce the spread of infection, can lead to negative social and psychological consequences, including loneliness, depression and anxiety [10-16]. Preliminary studies have confirmed that symptoms of anxiety, stress are common psychological reactions to the COVID-19 pandemic [1]. The very fact of being quarantined exacerbates people's anxiety reactions [11].

Researchers say that isolation exacerbates people's negative feelings. It reduces personal growth predictors associated with resources of coping with psychological trauma [17]. During the quarantine, people face the following stressors: fear of death and illness, disappointment and boredom, uncertainty about the future, guilt, frustration due to broken plans, and forced self-isolation [7,11,18-20]. However, currently, there is a lack of data on how people adapt to self-isolation due to the COVID-19 pandemic. Therefore, the objective of this article is to study the characteristics of students' features of adaptation to a situation of self-isolation in the face of the coronavirus pandemic.

The results of the studies suggest that young people (16-24 years old) constitute a risk group since they react badly to lockdown $[11,21]$. Therefore, During the time spent in the hospital, in addition to treatment, adolescents need social support that reduces their stress levels [22]. Such sensitivity to isolation measures is explained by age-related features [23]. Social inclusion is critical to the well-being and confidence of a young person [22]. Therefore, this study was conducted on a sample of students.

The issues related to a person's ability to cope with problems and stress are considered in the framework of the coping theory. Coping is defined as a set of cognitive and behavioral efforts aimed at managing conditions that exceed human capabilities [24]. The main purpose of coping is to reduce stress and achieve a balanced state of functioning [25]. There are different approaches to the classification of coping strategies. The two-factor model proposed by R.S. Lazarus and S. Folkman identifies 2 groups of strategies for behavior in a problem situation: an emotion- and problem-focused coping strategies [24]. Another two-factor coping model is presented in works studying the human response to trauma [27]. Two areas of response to the problem can be distinguished: approach and avoidance [28]. There are more complex coping behavior models. For example, in the work by S. Vallikala, V. Geetha, V. Jalaja Jayalakshmi, the most typical patterns of behavior are divided into procrastination, agitation, avoidance, adaptation, and apprehension [29]. An attempt to combine the views of different authors was made by N.N. Melnikova [30]. This author proceeds from the fact that the coping requires as follows: contact of the interacting parties, changes, and active actions.

Recently, researchers have come to the conclusion that human activity related to problem-solving can be of a different nature: reactive and proactive. Proactivity, in contrast to reactivity, has the following characteristics: responsibility [31]), over-situationality [31], anticipation [32], self-control and independence [33,34]. Proactive coping with problems can include different strategies: accumulation, adaptability, optimization, and compensation [35].

There are different ideas about which strategies are more successful and which are less. But most researchers conclude that the most successful adaptation is a combination of different strategies. This allowed formulating the following research hypothesis:

H1: The strategies used by students to adapt to self-isolating conditions will form stable complexes, which are manifested in close correlations between them.

The study of coping strategies in isolation situations was previously carried out in the framework of the analysis of the following problems: loneliness [23,36], restrictions on communication related to hospitalization [22], migration [37] and imprisonment [6]. It has been shown that the depression level is mediated by feelings of loneliness and coping strategies used by a person. In particular, loneliness reveals a negative correlation with 
strategies aimed at solving the problem and positively correlates with strategies aimed at avoiding the situation $[24,26,36]$. Social ties with the family and religious practices can facilitate social exclusion for migrants and refugees [37,38]. The results of these studies cannot be used to analyze the situation of self-isolation associated with the need to prevent the spread of coronavirus infection.

This type of isolation has a number of features. It is often recommendatory in nature. A person can be isolated together with family members or close friends. If necessary, a person can visit public places: a store, a hospital, etc. As a result, people maintain social interaction, but its volume and qualities can significantly decrease. It should be noted that the forced constant presence in a limited apartment space can create unnecessary stress in the family, exacerbate pre-existing conflicts. Thus, the currently available data allowed formulating the second hypothesis of the study:

$\mathrm{H} 2$ : In conditions of self-isolation caused by the need to prevent the spread of coronavirus, active behavior strategies and strategies involving self-change will dominate in the structure of students' adaptive behavior.

Researchers have noted differences between men and women in problem-solving. The results of longitudinal and transverse sections show that gender differences are the most significant at the age of 15-19 [39]. Women use more strategies are related to the search for social support $[40,41]$. They are more emotional in encountering difficulties than men $[29,39,41,42]$. Thus, the results of previous studies allow formulating the third hypothesis:

H3: Adaptation strategies for the self-isolation situation are different for male and female students.

\section{Methods}

\subsection{Procedure}

Data collection was carried out online using Google Forms in June 2020. To attract students, appeals were made through groups of student joint councils. Students could share a link to the survey with their friends on social networks.

\subsection{Participants}

The survey involved 370 people. In the course of data analysis, questionnaires of those who partially completed them or whose age exceeded 21 years old were excluded. As a result, 269 questionnaires were processed (135 female and 134 male ones). The age of the study participants ranged from 17 to 21 years old. The students' mode of study is full-time. $82 \%$ of respondents are single, $95 \%$ have no children.

\subsection{Measures}

During the survey, the study participants provided information about themselves (gender, age, place of study, year of study, faculty). To diagnose individual preferences in the selection of behavioral strategies in a situation of self-isolation related to the need to prevent the spread of coronavirus, a modification of the methodology "Adaptive Behavioral Strategies" was developed by N.N. Melnikova [30]. The methodology is built in the form of a description of 5 specific situations: 1. forced isolation within 14 days due to possible contact with a coronavirus patient; 2. total nation-wide self-isolation; 3. weakening of quarantine measures; 4. control of children's distance learning during self-isolation; 5. an increase in the number of conflicts in the family during self-isolation. For each situation, 
they propose a list of seven behavior options that correspond to the following strategies: environment changing, self-change, avoidance, self-immersion, passive self-representation, accommodating, waiting. In each situation, students were asked to determine which ways of behavior were most natural to them. Then they were to choose strategies that, from their point of view, are unacceptable in this situation. This is the way a person allows himself to behave, but does not necessarily do this. Each choice is translated into a point scale: 2 points - natural behavior, -2 points - unacceptable behavior, 1 point - additional options. The analysis determines the prevailing (maximum score) and rejected (minimum score) strategies.

The methodology allows analyzing individual preferences of strategies in self-isolating.

\subsection{Data analysis}

The study relied on a quantitative data analysis strategy. To select the method of mathematical data processing, a preliminary analysis of distribution parameters of the studied features was carried out (Table 1). It turned out that in the studied sample, the distribution parameters of the features under study significantly differ from the normal ones. Therefore, nonparametric methods were used as methods of mathematical processing of research results.

Table 1. Descriptive statistics for coping strategies in self-isolation situations.

\begin{tabular}{|l|c|c|c|c|c|c|c|}
\hline \multicolumn{1}{|c|}{ strategies } & $\mathbf{N}$ & $\mathbf{M}$ & SD & Skewness & Kurstosis & $\begin{array}{c}\text { Statistics of } \\
\text { Kolmogorov- } \\
\text { Smirnov }\end{array}$ & $\mathbf{p}$ \\
\hline environment changing & 269 & -0.87 & 3.78 & 0.502 & 0.800 & 0.12 & 0.00001 \\
\hline change of yourself & 269 & 6.86 & 3.13 & -0.727 & -0.614 & 0.21 & 0.00001 \\
\hline avoidance & 269 & -2.68 & 4.81 & 0.495 & -0.173 & 0.14 & 0.00001 \\
\hline immersion in yourself & 269 & 4.05 & 3.01 & -0.405 & 0.844 & 0.16 & 0.00001 \\
\hline $\begin{array}{l}\text { passive itself } \\
\text { representation }\end{array}$ & 269 & -2.24 & 3.98 & 0.871 & 1.142 & 0.15 & 0.00001 \\
\hline accommodating & 269 & 6.43 & 3.81 & -1.069 & 0.512 & 0.20 & 0.00001 \\
\hline $\begin{array}{l}\mid 7 \\
\text { waiting }\end{array}$ & 269 & -2.21 & 4.71 & 0.530 & -0.173 & 0.13 & 0.00001 \\
\hline
\end{tabular}

Since current data on stress coping strategies show that there are gender-related differences in their use [25], the data are described based on respondents' gender. The Mann-Whitney U-test was used to determine differences in the severity of adaptation strategies in self-isolating conditions among male and female representatives. To identify correlations between the studied behavioral strategies, Spearman correlation $\left(\mathrm{r}_{\mathrm{s}}\right)$ analysis was used. The statistical analysis was performed using SPSS Statistic 23.0.

\section{Results}

Table 2 shows the behavioral strategies that students prefer (positive values) and consider unacceptable in self-isolating conditions (negative values). The structure of adaptive behavior in students of both sexes coincides. In self-isolating conditions, they prefer to solve their problems by changing their own attitude to the situation or adapting (accommodating) to external requirements. The most unacceptable factors for students were avoidance, waiting, or passive self-representation strategies. As an additional strategy (values tend to zero), students use behavior aimed at changing conditions, up to confrontation with other people (environment changing). 
It should be noted that students prefer behavioral strategies aimed at their own inner world and rather do not accept outwardly directed strategies. There are differences in the preference of the most popular gender-related strategies throughout the sample (Table 2). These are environment changing and accommodating strategies. The first strategy is more common for men than for women. The second strategy is more preferred by women than men.

Table 2. Differences in preference for strategies by male and female students.

\begin{tabular}{|c|c|c|c|c|}
\hline \multirow{2}{*}{ Strategy of behavior } & \multicolumn{2}{|c|}{ Mean rank } & \multirow{2}{*}{$\begin{array}{c}\text { Mann- } \\
\text { Whitney U }\end{array}$} & \multirow{2}{*}{$\mathbf{p}$} \\
\hline & Male $N=134$ & Female $\mathrm{N}=135$ & & \\
\hline environment changing & 144.5 & 125.6 & 7778.0 & 0.046 \\
\hline change of yourself & 135.2 & 134.8 & 9013.0 & 0.959 \\
\hline avoidance & 135.4 & 134.6 & 8989.0 & 0.93 \\
\hline immersion in yourself & 127.2 & 142.8 & 7993.0 & 0.094 \\
\hline $\begin{array}{l}\text { passive itself } \\
\text { representation }\end{array}$ & 143.6 & 126.5 & 7897.0 & 0.07 \\
\hline accommodating & 119.8 & 150.1 & 7011.0 & 0.001 \\
\hline waiting & 139.8 & 130.3 & 8405.0 & 0.313 \\
\hline
\end{tabular}

The study found that students' preferences in using different behavioral strategies are interconnected. The tendency in self-isolating conditions to direct efforts to change one's own attitude to the situation (self-change) revealed an average positive correlation with accommodating $\left(\mathrm{r}_{\mathrm{s}}=0.522 ; \mathrm{p}=0.000001\right)$, a weak positive correlation with self-immersion $\left(r_{s}=0.451 ; p=0.00001\right)$, a very weak negative correlation with avoidance $\left(r_{s}=-0.167\right.$; $\mathrm{p}=0.006)$ and waiting $\left(\mathrm{r}_{\mathrm{s}}=-0.145 ; \mathrm{p}=0.02\right)$.

The desire to adapt to new conditions, to follow external rules (accommodating) revealed an average positive correlation with the preference for self-change strategy $\left(r_{s}=0.522 ; p=0.000001\right)$, a weak positive correlation with self-immersion strategy $\left(r_{s}=0.384\right.$; $\mathrm{p}=0.00001)$, a very weak negative correlation with avoidance $\left(\mathrm{r}_{\mathrm{s}}=-0.203 ; \mathrm{p}=0.001\right)$ and passive self-representation strategies $\left(\mathrm{r}_{\mathrm{s}}=-0.189 ; \mathrm{p}=0.002\right)$.

Correlations were found between the desire to change the situation (environment changing) and other outwardly directed strategies: avoidance $\left(r_{s}=0.383 ; p=0.00001\right)$, passive self-representation $\left(\mathrm{r}_{\mathrm{s}}=0.177 ; \mathrm{p}=0.004\right)$ and waiting $\left(\mathrm{r}_{\mathrm{s}}=0.265 ; \mathrm{p}=0.00001\right)$. The desire to change the environment, location (avoidance) correlates with passive outwardly directed strategies: passive self-representation $\left(\mathrm{r}_{\mathrm{s}}=0.415 ; \mathrm{p}=0.000001\right)$ and waiting $\left(r_{s}=0.533 ; p=0.000001\right)$. Self-immersion correlates with outwardly directed strategies and the ones focusing on contact with others: environment changing $\left(r_{s}=0.177 ; p=0.004\right)$ and passive self-representation $\left(\mathrm{r}_{\mathrm{s}}=0.142 ; \mathrm{p}=0.02\right)$. A stubborn demonstration of one's own position during self-isolation (passive self-representation) correlates with waiting $\left(\mathrm{r}_{\mathrm{s}}=0.501\right.$; $\mathrm{p}=0.000001)$.

\section{Discussion}

\subsection{Students' behavior strategies in a situation of self-isolation}

The novelty of this study lies in the fact that it allows describing the behavior of young people in self-isolating conditions as measures to prevent the spread of COVID-19. According to the results of the study, students prefer to use self-directed strategies in selfisolating conditions. This would suggest that students are particularly ready to change themselves. This change can occur under external influence, without an independent 
conscious analysis of the situation. It represents an externally conformal behavior, a willingness to follow the restrictions determined by lockdown. A more active position on self-change is also possible among the youth, since it changes the perception of the situation. This strategy involves the search for positive aspects in a difficult situation, the search for adequate forms of response to new conditions. As an option for behavior in a situation of self-isolation, students also consider avoidance, which consists in immersion in their inner world. The manifestations of this strategy are diverse and include as follows: the search for an alternative to the real world in the fantasy world, in the virtual space, or in religious and philosophical systems. This strategy is closest to addictive behavior [30], since self-immersion is often accompanied by alcohol or drugs consumption or by immersion in the virtual world. Spanish researchers believe that teens who use ineffective coping strategies for stressful situations (self-blame, rumination, blaming of others and catastrophising), show smartphone addiction. The authors suppose that gadgets act as a compensation for negative feelings and thoughts, which teenagers cannot overcome through the strategies they use [43].

Comparing the obtained results with the data of other researchers, it should be noted that they are typical for this age group. In particular, the analysis of behavior strategies of students and resident physicians showed that in order to cope with difficult learning conditions, they use active strategies more often rather than passive strategies [44]. But the authors note that a significant proportion of respondents use avoidance strategies. In general, students changed their attitude to studies, concentrating on its positive aspects, which allowed them to cope with difficult conditions [25]. In the study of bullying victims aged 12-19, it was found that in such situations they recommend using either passive strategies, such as avoidance, or risky ones, such as open confrontation [45]. Italian researchers suggest that "proactive coping strategy such as direct confrontation exerts a protective effect on emotional symptoms, an effect which is fully mediated by resilience" [46]. They come to this conclusion based on the discovered fact that the influence of the confrontational coping strategy on the emotional symptoms caused by bullying is mediated by the resilience of schoolchildren aged 13-19 [45].

\subsection{The correlation structure of students' coping behavior}

Two groups of positively correlating strategies can be distinguished in the structure of students' coping behavior. Between the three most preferred behavior strategies used by students (accommodating, self-change and self-immersion), there is an average positive correlation. Similar correlations were found between strategies that are not popular among students and characterized by an outward orientation (environment changing, waiting, avoidance and passive self-representation). Certain strategies from these two groups have weak negative correlations. The discovered complexes of strategies suggest that there are stable combinations of response strategies, which are behavior variations in a situation of self-isolation, considered by students. From the students' point of view, self-directed strategies are the most probable vector of their behavior in difficult situations associated with the need for self-restraint imposed by self-isolating conditions. While outwardly directed strategies are not considered as possible alternatives to behavior in this situation. This may be specific to the situation of self-isolation, since it does not imply active contacts with the external environment.

\subsection{Gender differences in students' behavior in a situation of self-isolation}

Gender differences in the preferences of individual strategies found during the study are consistent with the existing data on differences in the behavior of different gender. Thus, 
men were more committed to a strategy of active environmental change than women. Women tend to passively submit to external pressure than men. It was previously noted that women use a more emotion-oriented approach and are more likely to use unhelpful (passive) coping strategies than men [47]. It was also found that boys aged 12-19, unlike girls of the same age, recommend that in the case of bullying the offender should be fought back, while girls recommend ignoring the offender [45]. Compared to male athletes, Ukrainian female youth athletes are more likely to use a self-incriminating strategy [42].

At the same time, the analysis of coping strategies of Indian students showed different trends. The adaptation strategy turned out to be typical for male students, while the waiting strategy - for female students [29]. Such discrepancies may be related to the difference in cultural and historical conditions for the development of students from different countries. Moreover, there is evidence of the existence of such differences [40]. Differences in the data can be determined by differences in the classification and measurement of coping strategies.

\section{Conclusion}

The COVID-19 pandemic and subsequent self-isolation measures have led to significant changes in students' lifestyles. They switched to distance learning and online communication with their friends and relatives. Forced staying in an enclosed space of an apartment for many days is a challenge for any relationship, and online learning increases stress for students. Therefore, this article is devoted to the study of coping with the problems caused by lockdown due to the need to prevent the spread of COVID-19, introduced in Russia in April 2020. The hypotheses formulated during the study were confirmed by empirical data. The results showed that in order to adapt to changed conditions, students prefer to use strategies aimed at self-change and consider strategies aimed at changing the environment unacceptable. Strategies preferred and rejected by students are stable complexes in students' behavior. The existing differences in the preference of certain adaptation strategies between male and female students indicate that men are more active than women.

\section{References}

1. R.P. Rajkumar, Asian J. Psychiatr., 52, 102066 (2020).

2. J.D. Elhai, H. Yang, D. McKay, and G.J.G. Asmundson, J. Affect. Disord., 274 (2020).

3. M. Naeim, Asian J. Psychiatr., 51 (2020).

4. M.J. Constantino, R.K. Sommer, B.J. Goodwin, A.E. Coyne, and E.C. Pinel, J. Psychother. Integr., 29 , 4 (2019).

5. R.B. Viana and C.A.B. de Lira, Games Health J., 9, 3 (2020).

6. L. Guillod, S. Habersaat, M. Suter, T. Jeanneret, C. Bertoni, P. Stéphan, and S. Urben, Encephale, 44, 2 (2018).

7. S. Sahoo, A. Mehra, V. Suri, P. Malhotra, L.N. Yaddanapudi, G. Dutt Puri, and S. Grover, Asian J. Psychiatr., 53 (2020).

8. A.L. Heck, J.A. Sheng, A.M. Miller, S.A. Stover, N.J. Bales, S.M.L. Tan, R.M. Daniels, T.K. Fleury, and R.J. Handa, Stress, 23, 4 (2020).

9. A. Mudra Rakshasa and M.T. Tong, Front. Behav. Neurosci., 14 (2020).

10. G.J. Rubin and S. Wessely, BMJ, 368 (2020). 
11. S.K. Brooks, R.K. Webster, L.E. Smith, L. Woodland, S. Wessely, N. Greenberg, and G.J. Rubin, Lancet, 395 (2020).

12. L. Duan and G. Zhu, The Lancet Psychiatry, 7, 4 (2020).

13. C. Wang, R. Pan, X. Wan, Y. Tan, L. Xu, C.S. Ho, and R.C. Ho, Int. J. Environ. Res. Public Health, 17, 5 (2020).

14. B.D. Thombs, L. Kwakkenbos, M.E. Carrier, A. Bourgeault, L. Tao, S. Harb, M. Gagarine, D. Rice, L. Bustamante, K. Ellis, D. Duchek, Y. Wu, P.M. Bhandari, D. Neupane, A. Carboni-Jiménez, R.S. Henry, A. Krishnan, Y. Sun, B. Levis, et al., J. Psychosom. Res., 135 (2020).

15. S. Dubey, P. Biswas, R. Ghosh, S. Chatterjee, M.J. Dubey, S. Chatterjee, D. Lahiri, and C.J. Lavie, Diabetes Metab. Syndr. Clin. Res. Rev., 14, 5 (2020).

16. S. Chen, Trials, 21, 1 (2020).

17. S. Dickinson, J. Posit. Psychol., (2020).

18. A. Desclaux, D. Badji, A.G. Ndione, and K. Sow, Soc. Sci. Med., 178 (2017).

19. J.A. Wilken, P. Pordell, B. Goode, R. Jarteh, Z. Miller, B.G. Saygar, L. Maximore, W.M. Borbor, M. Carmue, G.W. Walker, and A. Yeiah, Prehosp. Disaster Med., 32 (2017).

20. D. Carr, K. Boerner, and S. Moorman, J. Aging Soc. Policy, 32, 6 (2020).

21. M.R. Taylor, K.E. Agho, G.J. Stevens, and B. Raphael, BMC Public Health, 8, 1 (2008).

22. D. Maor and K. Mitchem, J. Adolesc. Res., 35, 2 (2020).

23. J. Vanhalst, K. Luyckx, S. Van Petegem, and B. Soenens, J. Youth Adolesc., 47, 1 (2018).

24. L. Galiana, J.M. Tomás, I. Fernández, and A. Oliver, Front. Psychol., 11 (2020).

25. N. Abouammoh and E. Alfaris, BMC Med. Educ., 20 (2020).

26. E.C. Schoenmakers, T.G. van Tilburg, and T. Fokkema, Eur. J. Ageing, 12, 2 (2015).

27. T. Buqo, E.F. Ward-Ciesielski, and J.K. Krychiw, OMEGA - J. Death Dying (2020).

28. C.E. Waugh, E.Z. Shing, and R.M. Furr, Anxiety, Stress Coping, 33, 5 (2020).

29. S. Vallikala, V. Geetha, and V.J. Jayalakshmi, Int. J. Innov. Technol. Explor. Eng., 8, 9S2 (2019).

30. N.N. Melnikova, Diagnosis of socio-psychological adaptation of personality, SUSU, Chelyabinsk (2004).

31. E.S. Starchenkova, Bull. St. Petersbg. Univ. Sociol., 2 (2009).

32. A.A. Bekhter, Probl. High. Educ., 1 (2019).

33. S.R. Covey, The seven habits of highly effective people, Alpina Business Books, Moscow (2018).

34. E.S. Starchenkova, Bull. St. Petersbg. Univ. Sociol., 1 (2012).

35. S.K. Parker, Y. Wang, and J. Liao, Annu. Rev. Organ. Psychol. Organ. Behav., 6, 1 (2019).

36. A.D. La Fuente, E.C. Chang, O. Cardeñoso, and O.D. Chang, Span. J. Psychol., 21, (2018).

37. F. Rios Casas, D. Ryan, G. Perez, S. Maurer, A.N. Tran, D. Rao, and I.J. Ornelas, J. Racial Ethn. Heal. Disparities, 7 (2020).

38. V. Markova and G.M. Sandal, Front. Psychol., 7, 1435 (2016). 
39. K.M. Flannery, A. Vannucci, and C.M.C. Ohannessian, J. Adolesc. Heal., 62, 3 (2018).

40. N. Coppari, B. Barcelata Eguiarte, L. Bagnoli, G. Codas Zavala, H. López Humada, and Ú. Martínez Cañete, Univ. Psychol., 18, 1 (2019).

41. D. Kalka and B. Karcz, Polish Psychol. Bull., 47, 3 (2016).

42. D. Ivaskevych, O. Borysova, S. Fedorchuk, S. Tukaiev, I. Kohut, V. Marynych, Y. Petrushevskyi, O. Ivaskevych, and I. Mihăila, J. Phys. Educ. Sport, 19, 2 (2019).

43. Extremera, Quintana-Orts, Sánchez-Álvarez, and Rey, Int. J. Environ. Res. Public Health, 16, 17 (2019).

44. S.A.R. Al-Dubai, R.A. Al-Naggar, M.A. Alshagga, and K.G. Rampal, Malaysian J. Med. Sci., 18, 3 (2011).

45. R. Sittichai and P.K. Smith, J. New Approaches Educ. Res., 7, 1 (2018).

46. A. Brighi, C. Mameli, D. Menin, A. Guarini, F. Carpani, and P.T. Slee, Int. J. Environ. Res. Public Health, 16, 24 (2019).

47. N. Abouammoh and E. Alfaris, BMC Med. Educ., 20 (2020). 